\title{
Opsporen van prostaatkanker in uitademingslucht met behulp van een draagbare elektronische neus
}

\author{
Claire G. Waltman' • Joep G. H. van Roermund ${ }^{1}$ \\ Published online: 16 January 2018 \\ (c) The Author(s) 2017. This article is an open access publication.
}

\section{Samenvatting}

De laatste jaren zijn verschillende non-invasieve technieken onderzocht om opsporing van prostaatkanker te verbeteren. Dit onderzoek gaat over de analyse van uitademingslucht door een geavanceerde, gebruiksvriendelijke en draagbare elektronische neus, de Aeonose ${ }^{\mathrm{TM}}$. Gebruik van deze technologie kan leiden tot verbeterde opsporing van prostaatkanker. Uitademingslucht van 85 patiënten werd geanalyseerd. De groep bevatte 32 patiënten met nog onbehandelde prostaatkanker. De controlegroep bestond uit 53 patiënten; 30 met negatieve prostaatbiopten en 23 met benigne prostaathyperplasie. Om onderscheid te maken tussen deze groepen werd een artificieel neuraal netwerk (ANN) getraind. Dit model toont aan dat het mogelijk is om patiënten met prostaatkanker en controlepatiënten van elkaar te onderscheiden. De oppervlakte onder de curve bedroeg 0,79, met een sensitiviteit en specificiteit van respectievelijk 0,84 $(95 \%$-BI = 0,66-0,94) en 0,70 $(95 \%-\mathrm{BI}=0,55-0,81)$. De negatief voorspellende waarde is 0,88 . Deze eerste resultaten zijn veelbelovend.

Trefwoorden prostaatkanker · uitademingslucht · elektronische neus · volatile organic compound (VOC)

\section{Detecting prostate cancer by analyzing exhaled-breath using a portable electronic nose (Aeonose ${ }^{\mathrm{TM}}$ )}

\begin{abstract}
In the last decade, several non-invasive methods have been researched in order to improve detection of prostate cancer (PCa). This study investigated the possibility of detecting PCa based on exhaled-breath analysis using an advanced, easy-to-use, portable electronic nose ('Aeonose ${ }^{\mathrm{TM}}$ '). Exhaled-breath was probed from 85 patients. Within this population, 32 were diagnosed with primary $\mathrm{PCa}$, and 53 patients were used as controls: 30 having negative biopsies, 23 with benign prostate hyperplasia. In order to differentiate between groups, an artificial neural network was trained. This trained model showed an area under the curve of 0.79 with a sensitivity and specificity of $0.84(95 \% \mathrm{CI}=0.66-0.94)$ and $0.70(95 \%$ $\mathrm{CI}=0.55-0.81)$ respectively, when comparing primary PCa and controls. Negative predictive value found was 0.88 . In conclusion, these promising results imply Aeonose ${ }^{\mathrm{TM}}$ exhaled-breath analysis can be used to detect PCa.
\end{abstract}

Keywords prostate cancer $\cdot$ exhaled-breathe $\cdot$ electronic nose $\cdot$ volatile organic compounds (VOCs)

\section{Introductie}

Al sinds de Griekse oudheid is bekend dat uitademingslucht informatie bevat over iemands gezondheidstoestand. Uit onderzoek is gebleken dat honden een zeer goed ontwikkeld reukorgaan hebben en concentraties van 0,001 deeltjes

dr. Joep G. H. van Roermund joep.van.roermund@mumc.nl

1 afdeling Urologie, Maastricht Universitair Medisch Centrum, Maastricht, Nederland per miljoen kunnen detecteren in de vorm van vluchtige organische stoffen, volatile organic compounds (VOCs) [1]. Dit zijn stoffen die het menselijk lichaam produceert gedurende de dagelijkse (normale) metabole processen en in de circulatie terechtkomen om vervolgens te worden uitgescheiden in onder andere urine en uitademingslucht [2]. In een onderzoek van Cornu et al. is reeds aangetoond dat speciaal getrainde honden prostaatkanker kunnen ruiken in urine, met een sensitiviteit en specificiteit van bijna $91 \%$ [3]. Honden dienen getraind te worden om ziek en gezond van elkaar te kunnen onderscheiden. Dit is een intensief en kostbaar trainingstraject. Daarbij hebben hon- 
den een beperkte levensduur. De elektronische neus is een nieuwe technologische innovatie die deze problemen kan ondervangen. Het is een interessante ontwikkeling in het kader van de opsporing van prostaatkanker. Voorheen bestond de standaarddiagnostiek van prostaatkanker uit louter het rectaal toucher, een transrectale echo van de prostaat en het serum-PSA. Inmiddels heeft de MRI zijn intrede gedaan in de primaire diagnostiek en zijn er moleculaire markers. Bij de besluitvorming over het al dan niet nemen van een biopt, helpt de prostaatkanker-risicocalculator [4]. Geen van deze methoden is echter afdoende sensitief dan wel specifiek. De gouden standaard voor het vaststellen van prostaatkanker is het nemen van prostaatbiopten. De kans op een fout-negatieve uitslag bij een eerste biopt is vrij hoog, namelijk 20-25\%. Bij een tweede biopt ligt dit percentage rond de 10-15 [5-7]. Het is dan ook wenselijk om een nieuwe diagnostische test te ontwikkelen, die beter kan discrimineren tussen het gezonde individu en de patiënt met prostaatkanker. Door betere discriminatie zullen minder patiënten worden blootgesteld aan de nadelen en risico's van prostaatbiopten. Vanuit dit oogpunt is het interessant om te weten of een elektronische neus op basis van analyse van uitademingslucht kan vaststellen of er sprake is van prostaatkanker $[8,9]$.

In deze prospectieve pilotstudie is met een draagbare, op een accu werkende elektronische neus (Aeonose ${ }^{\mathrm{TM}}$ ) onderzocht of prostaatkanker kan worden vastgesteld op basis van een uitademingsluchtprofiel.

\section{Materiaal en methoden}

Het huidige onderzoek is opgezet als een prospective proof of concept study en werd tussen juli 2016 en februari 2017 in onze kliniek uitgevoerd met toestemming van de $\mathrm{Me}$ disch Ethische Toetsingscommissie (METC). In dit onderzoek werden 85 patiënten geïncludeerd, die werden verdeeld over drie groepen: onbehandelde prostaatkanker $(n=$ $32)$, negatieve prostaatbiopten $(n=30)$ en benigne prostaathyperplasie $(\mathrm{BPH})$ zonder klinische verdenking op prostaatkanker $(n=23)$. Voorwaarde voor inclusie was beschikbaarheid van een recente serum-PSA-waarde, alsmede een histopathologisch rapport van de prostaatbiopten. Het aantal te nemen weefselbiopten is afhankelijk van het prostaatvolume (cc), zoals beschreven in de PRIAS-studie [10]. Deelname aan het onderzoek was niet mogelijk bij een maligniteit in de voorgeschiedenis of tekenen van een actieve infectie, om mogelijke interferentie met de data te voorkomen. Alle deelnemers hebben schriftelijk ingestemd met deelname aan het onderzoek.

\section{Werking van de Aeonose ${ }^{\mathrm{Tm}}$}

De Aeonose $\mathrm{TM}^{\mathrm{TM}}$ (fig. 1) is een draagbare elektronische neus, waarin zich drie metaaloxide sensoren bevinden met verschillende oppervlakte-eigenschappen. Een groot aantal vluchtige verbindingen (volatile organic compounds (VOC's)) in de uitademingslucht kan reageren met de sensoroppervlakken van deze 'neus' en door een redoxreactie een verandering in het geleidend vermogen van de sensor teweegbrengen. Dit redoxeffect is afhankelijk van de aanwezige VOC's in de uitademingslucht die over de sensoren wordt geleid, de materiaaleigenschappen van de gebruikte sensoren en het aangeboden temperatuurprofiel. De patiënt dient gedurende 5 minuten rustig in- en uit te ademen via de Aeonose ${ }^{\mathrm{TM}}$. Een (disposable) mondstuk met Hepa-filter voorkomt eventuele besmetting. De patiënt ademt in via een koolstoffilter om mogelijke invloed van verstorende

Figuur 1 De Aeonose ${ }^{\mathrm{TM}}$
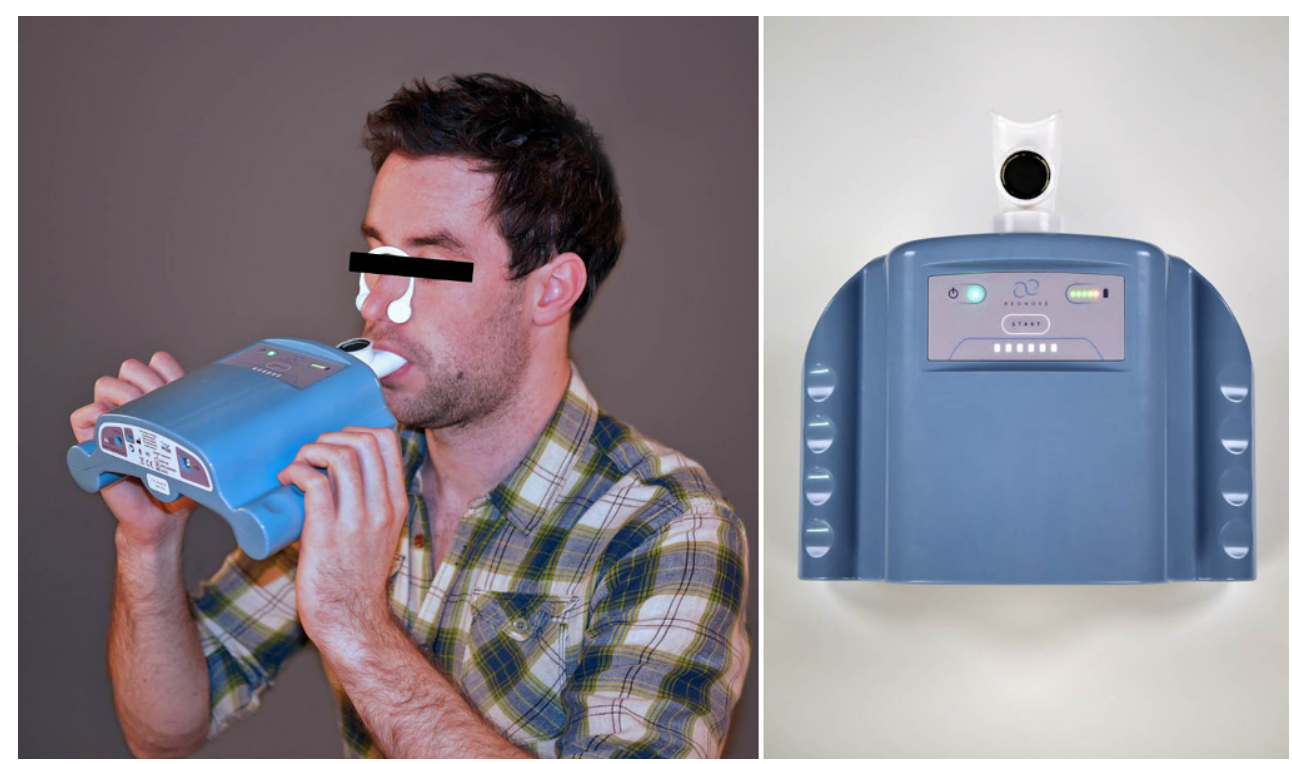
Tabel 1 Baselinekarakteristieken van de gehele studiepopulatie

\begin{tabular}{|c|c|c|c|c|}
\hline & primaire prostaatkanker & controlegroep $^{\mathrm{a}}$ & totaal & $p$-waarde \\
\hline$n$ & 32 & 53 & 85 & - \\
\hline $\begin{array}{l}\text { gem. leeftijd } \\
\text { (range/SD) }\end{array}$ & $\begin{array}{l}67,66 \\
(52-81 / 7,76)\end{array}$ & $\begin{array}{l}67,23 \\
(50-80 / 6,48)\end{array}$ & $\begin{array}{l}67,39 \\
(50-81 / 6,93)\end{array}$ & 0,784 \\
\hline $\begin{array}{l}\text { gem. serum-PSA (ng/ml) } \\
\text { (range/SD) }\end{array}$ & $\begin{array}{l}9,27 \\
(4,60-28,50 / 4,93)\end{array}$ & $\begin{array}{l}5,63 \\
(0,90-15,40 / 3,50)\end{array}$ & $\begin{array}{l}7,00 \\
(0,90-28,50 / 4,44)\end{array}$ & $<0,000$ \\
\hline $\begin{array}{l}\text { gem. prostaatvolume (cc) } \\
\text { (range/SD) }\end{array}$ & $\begin{array}{l}52,38 \\
(24-130 / 24,69)\end{array}$ & $\begin{array}{l}70,96 \\
(20-218 / 40,38)\end{array}$ & $\begin{array}{l}63,55 \\
(20-218 / 36,28)\end{array}$ & 0,021 \\
\hline gem. Gleason-score & $7,21(6-9)$ & - & - & - \\
\hline \multicolumn{5}{|l|}{ Gleason-score } \\
\hline $3+3$ & 9 & - & - & - \\
\hline $3+4$ & 9 & - & - & - \\
\hline $4+3$ & 5 & - & - & - \\
\hline $4+4$ & 6 & - & - & - \\
\hline $4+5$ & 2 & - & - & - \\
\hline $5+4$ & 1 & - & - & - \\
\hline gem. BMI (SD) & $25,78(2,91)$ & $26,89(3,59)$ & $26,47(3,38)$ & 0,144 \\
\hline
\end{tabular}

aatiënten met negatieve biopten $(n=30)$ gecombineerd met de BPH-groep $(n=23)$

$S D$ standaarddeviatie, $B M I$ body mass index, $P S A$ prostaatspecifiek antigeen

stoffen in de omgevingslucht te verminderen. Na deze 5 minuten kan de Aeonose ${ }^{\mathrm{TM}}$ op tafel geplaatst worden en start het spoelen van de sensoren met schone lucht. Vervolgens wordt een preconcentrator verwarmd (een Tenax-buisje) waaraan VOC's geadsorbeerd zijn. Ook deze worden langs de sensoren geleid, waarna een tweede regeneratie met schone lucht plaatsvindt. Het totale meetproces duurt op deze manier 15 minuten, waarna de Aeonose ${ }^{\mathrm{TM}}$ weer gereed is voor een volgende meting. De gegenereerde data worden via een bluetoothverbinding naar een iPad verstuurd, en doorgestuurd naar een server in Amsterdam. Daar worden de meetwaarden door een getraind artificieel neuraal netwerk (ANN) geleid, waardoor binnen enkele seconden de uitslag ter beschikking komt. Dit resultaat wordt teruggestuurd naar de iPad.

Het ontwikkelen van een algoritme om de verschillende patronen in uitademingslucht van elkaar te kunnen onderscheiden, vereist training van een ANN.

\section{Trainen van een artificieel neuraal netwerk}

Bij het trainen van een ANN worden initieel ademprofielen verzameld, tezamen met een gekende diagnose, om een neuraal netwerk te trainen het ademprofiel te herkennen. Een enkel ademprofiel bevat duizenden waarden voor de geleidbaarheid, voortkomend uit de moleculen in de uitgeademde lucht, die interacteren met de metaaloxidesensoren in de Aeonose ${ }^{\mathrm{TM}}$. Om overfitting van deze grote hoeveelheid data te voorkomen, moeten deze data eerst gecomprimeerd worden [11]. Na voorbewerking (preprocessing), worden de gegenereerde data gereduceerd met behulp van een Tucker3-solution, waardoor er een vector van gelimiteerde grootte voor elke patiënt kan worden gegenereerd [13]. Dit wordt gedaan om een zogenaamde Voodooanalyse te voorkomen, ofwel een analyse waarbij onderscheid tussen de verschillende groepen wordt gemaakt, ongeacht de gemeten uitkomstwaarden [11]. Tezamen met de patiëntclassificatie worden de gevonden waarden gebruikt voor het trainen van het ANN. Resultaten werden gegenereerd met behulp van de leave-10\%-out crossvalidatie. Via deze methode wordt $10 \%$ van de patiënten geclassificeerd, wat is gebaseerd op het berekende algoritme van de overige $90 \%$. Deze $10 \%$ heeft steeds een andere samenstelling, die opnieuw geclassificeerd wordt op basis van de resterende $90 \%$. Dit proces wordt tien keer herhaald, totdat alle patiënten geclassificeerd zijn op basis van het ANN. Alle resultaten in deze studie zijn op deze wijze tot stand gekomen. De nauwkeurigheid van het algoritme is gekwantificeerd door middel van de oppervlakte onder de curve (AUC), waarbij de analyse van een ROC-curve is gebruikt.

\section{Statistische analyse}

Basisgegevens van de patiënten werden verzameld met een korte vragenlijst en verkregen uit het medisch dossier (o. a. serum-PSA). Verschillen in de basisgegevens werden getoetst middels een onafhankelijke $t$-toets, Fisher-exacttest of een Pearsons chi-kwadraattoets. De ROC-curves zijn tot stand gekomen middels de leave-10\%-out kruisvalidatiemethode, waarbij de nauwkeurigheid van het algoritme is gekwantificeerd middels een AUC. Een $p$-waarde kleiner dan 0,05 werd beschouwd als statistisch significant. De 


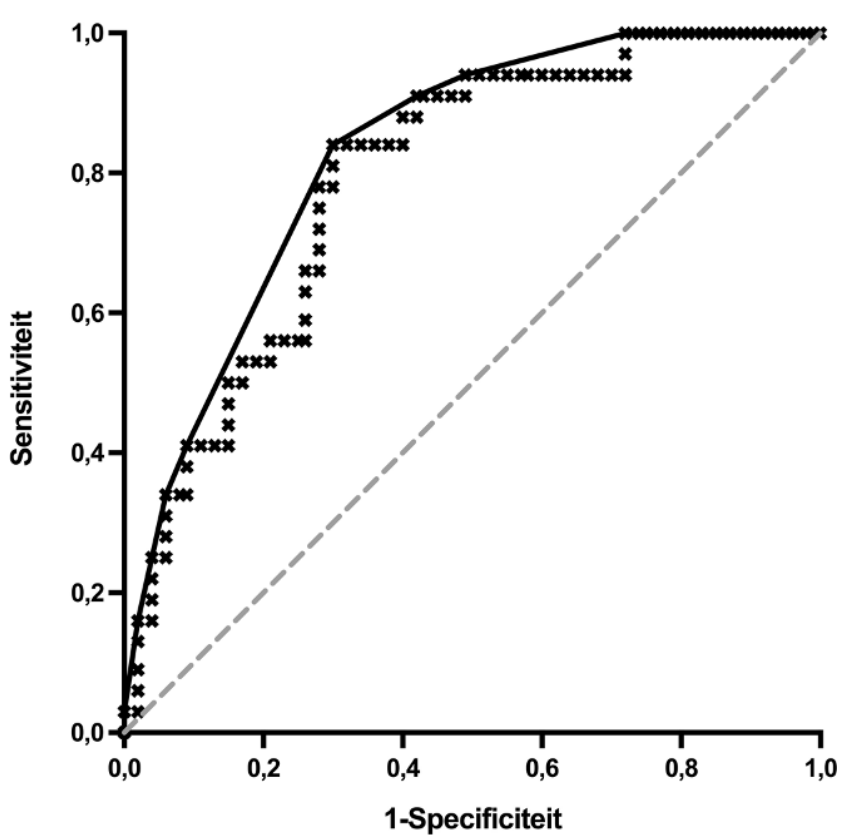

Figuur 2 ROC-curve van de relatie tussen de verschillen in uitademingslucht van patiënten met prostaatkanker en controles

analyses zijn uitgevoerd met behulp van IBM SPSS statistics for Windows, versie 23.0 (IBM Corp, Armonk, NY, USA). Een gedetailleerde beschrijving van de data-analyse die voor het ANN is gebruikt, is beschreven door Kort et al. [12].

\section{Resultaten}

Karakteristieken van de in het onderzoek opgenomen patiënten zijn weergegeven in tab. 1. Alle deelnemers hebben de ademtest succesvol afgelegd. De gemiddelde leeftijd en body mass index (BMI) was vergelijkbaar tussen de groepen. Het gemiddelde serum-PSA en het prostaatvolume was significant verschillend. De distributie van de Gleason-score binnen de prostaatkankergroep is eveneens weergegeven in tab. 1.

In de subgroepanalyse werd de groep met prostaatkanker $(n=32)$ vergeleken met de groep met negatieve biopten $(n=30)$. De gemiddelde leeftijd was 67,7 jaar, met een standaarddeviatie (SD) van 7,0. Er werd geen statisch significant verschil gevonden tussen de groepen $(p=0,640)$. Het gemiddelde serum-PSA in de prostaatkankergroep was $9,27 \mathrm{ng} / \mathrm{ml}(\mathrm{SD}=4,93)$, versus $7,09 \mathrm{ng} / \mathrm{ml}(\mathrm{SD}=3,65)$ in de negatieve bioptengroep $(p=0,054)$. Het gemiddelde prostaatvolume in de prostaatkankergroep was $52,38 \mathrm{cc}$, versus $81,07 \mathrm{cc}$ in de controlegroep $(p=0,003)$.

De ROC-curve in fig. 2 geeft het onderscheidend vermogen weer tussen de prostaatkanker- en de controlegroep van

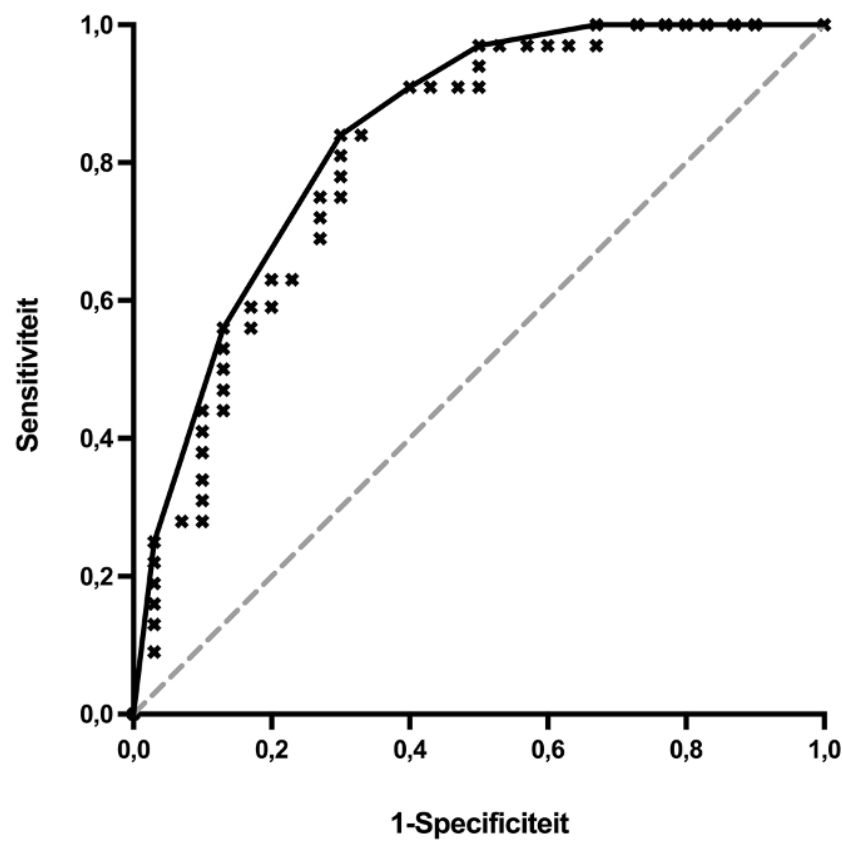

Figuur 3 ROC-curve van de relatie tussen de verschillen in uitademingslucht van patiënten met prostaatkanker en patiënten met negatieve biopten

de Aeonose ${ }^{\mathrm{TM}}(\mathrm{AUC}=0,79)$. De nauwkeurigheid van het model is 0,77 . De sensitiviteit en specificiteit zijn respectievelijk 0,84 (95\%-BI =0,66-0,94) en 0,70 (95\%-BI = $0,55-0,81)$. De negatief voorspellende waarde (NVW) is 0,88 . Het onderscheidend vermogen van het model tussen de groep met prostaatkankerpositieve en -negatieve biopten is weergegeven in fig. 3. De AUC van het model is 0,81 , met een nauwkeurigheid van 0,75 . De sensitiviteit en de specificiteit zijn respectievelijk 0,84 $(95 \%$-BI $=0,66-0,94)$ en $0,70(95 \%-\mathrm{BI}=0,50-0,85)$. De NVW is 0,81 .

\section{Discussie}

Het doel van deze pilotstudie was te onderzoeken of een elektronische neus onderscheid kan maken tussen patiënten met bewezen prostaatkanker en controlepatiënten. De Aeonose $^{\mathrm{TM}}$ heeft in deze studie een hoge sensitiviteit en specificiteit voor het detecteren van prostaatkanker.

In het laatste decennium zijn er meerdere moleculaire markers op de markt gekomen voor de diagnostiek van prostaatkanker. Dit zijn onder andere prostaatkankerantigeen 3 (PCA3) en het 4-kallikrein (4K) panel. Dergelijke testen zijn echter kostbaar en ook zijn de uitslagen niet direct beschikbaar. De sensitiviteit (PCA3 0,67; 4K-panel 0,74 ) en de specificiteit (PCA3 0,83; 4K-panel 0,60) van de tests biedt ruimte voor verbetering [14].

De aanschafprijs van de Aeonose ${ }^{\mathrm{TM}}$ wordt geschat op $1.500 €$; de analysekosten worden geschat op $140 €$ (dit is 
inclusief 15 minuten tijd van een verpleegkundige). Omdat het een point-of-care-apparaat is, heeft men in de kliniek vrijwel direct de beschikking over de testuitslag, en gaat er geen tijd verloren met inzetten van aanvullende diagnostiek.

De laatste jaren is er bij de diagnostiek steeds meer aandacht gekomen voor het gebruik van VOC-patroonherkenning in uitademingslucht bij een brede variatie aan ziektebeelden (o. a. tuberculose, Barret-oesofagus en hoofd- en halstumoren) [15-18]. Wij vonden slechts twee studies over het vaststellen van prostaatkanker op basis van uitademingsluchtanalyse. Een studie door Peng et al. [19] onderzocht 18 patiënten met prostaatkanker en vergeleek de uitkomst met die van 22 gezonde individuen. Nakhleh et al. deed hetzelfde met 11 patiënten met prostaatkanker en vergeleek hun uitkomsten met die van 35 gezonde individuen. Deze groep werd echter niet meegenomen in de statistische analyse van het onderzoek, omdat de studiepopulatie te klein was. Het voornaamste verschil tussen deze technieken en de onze is dat GC-MS VOC's identificeert en kwantificeert en de Aeonose ${ }^{\mathrm{TM}}$ het collectieve VOC-patroon bepaalt. Desalniettemin tonen de meeste studies die gebruikmaken van de VOC-patroonherkenning veelbelovende resultaten, die wijzen in de richting van toekomstig diagnostisch hulpmiddel. VOC-patroonherkenning is, in tegenstelling tot de Aeonose $^{\mathrm{TM}}$, echter een tijdrovende en kostbare methode.

De Aenose ${ }^{\mathrm{TM}}$ heeft echter beperkingen. Ten eerste kan contaminatie optreden door variatie in samenstelling van de omgevingslucht, eetgewoonten van mensen of andere op dat moment nog niet geopenbaarde ziekte. In onze studie zijn alle metingen uitgevoerd op de urologische polikliniek, om de omgevingsvariatie tot een minimum te beperken. De omgevingslucht wordt grotendeels gezuiverd door de koolstoffilters in de Aeonose ${ }^{\mathrm{TM}}$. De invloed van het uitvoeren van metingen in meerdere ruimten, met mogelijk een andere samenstelling van de omgevingslucht, is nog niet bestudeerd. In de studie van Peng et al. [19] werden aan de patiënten strikte eisen gesteld. Zo mochten deelnemers in de 12 uur voorafgaand aan de analyse niet roken of alcohol gebruiken. Een ademtest werd ook niet uitgevoerd binnen vier dagen na het biopteren van de prostaat. De invloed van dergelijke factoren moet in toekomstige studies verder onderzocht worden. De invloed van nog niet ontdekte maligniteiten elders in het lichaam op het moment dat getest wordt op prostaatkanker, is ook nog niet bekend. Van Goor et al. [20] hebben aangetoond dat het mogelijk is om onderscheid te maken tussen diverse maligniteiten op basis van de analyse van uitademingslucht. Helaas was prostaatkanker in deze studie niet als ziektebeeld geïncludeerd. Een tweede beperking is de grootte van de studiepopulatie, hoewel onze studie naar het vaststellen van prostaatkanker op basis van analyse van uitademingslucht de grootste tot dusver is. Grotere studies zijn nodig om de validiteit van de huidige resultaten te bevestigen.
Een ander essentieel aspect is de samenstelling van de controlegroep. In onze studiepopulatie bestond de controlegroep uit mannen met (herhaalde) negatieve biopten of mannen bij wie BPH was vastgesteld. Binnen de negatieve bioptengroep werd er bij 14 van de 30 patiënten op één moment in de tijd een biopsie verricht. Bij de overige 16 werden op twee of meer momenten een biopt genomen. Potentieel zijn er patiënten aan deze groep toegewezen die een fout-negatieve uitslag hadden van de biopsie. Dit risico is aanzienlijk gereduceerd doordat meer dan de helft meer dan één keer biopten heeft laten afnemen. Bovendien kunnen ook diegenen met negatieve biopten en een afwijkende ademtest een nog niet aangetoonde prostaattumor hebben. Omdat dit onderzoek nog in de kinderschoenen staat, bestond onze studiepopulatie uit een selecte groep patiënten. Als de Aeonose ${ }^{\mathrm{TM}}$ voor prostaatkanker getraind is, kan prostaatkanker worden onderscheiden van andere maligniteiten of infecties. Dit zal er ook toe leiden dat de techniek minder gevoelig is voor storingen.

Het primaire doel van deze pilotstudie bestond uit het antwoord geven op de vraag of de Aeonose ${ }^{\mathrm{TM}}$ onderscheid kan maken tussen het gezonde individu en de patiënt met prostaatkanker. Omdat een uroloog met name is geïnteresseerd in het vinden van significante prostaatkanker, is het interessant om in een vervolgstudie het onderscheidend vermogen van de Aeonose ${ }^{\mathrm{TM}}$ voor niet-significante en significante prostaatkanker na te gaan (Gleason 7).

\section{Conclusie}

Het resultaat van deze prospective proof of concept study toont aan dat het, op basis van analyse van uitademingslucht middels een elektronische neus $\left(\right.$ Aeonose $\left.^{\mathrm{TM}}\right)$, onderscheid gemaakt kan worden tussen patiënten met prostaatkanker en controles.

Open Access This article is distributed under the terms of the Creative Commons Attribution 4.0 International License (http:// creativecommons.org/licenses/by/4.0/), which permits unrestricted use, distribution, and reproduction in any medium, provided you give appropriate credit to the original author(s) and the source, provide a link to the Creative Commons license, and indicate if changes were made.

\section{Literatuur}

1. Waggoner LP, Jones MH, Williams M, et al. Effects of extraneous odors on canine detection. Proceedings SPIE 3575, enforcement and security technologies (28 december 1998). Event: enabling technologies for law enforcement and security. Boston. 1998.

2. Haick H, Broza YY, Mochalski P, et al. Assessment, origin, and implementation of breath volatile cancer markers. Chem Soc Rev. 2014;43(5):1423-49. 
3. Cornu JN, Cancel-Tassin G, Ondet V, et al. Olfactory detection of prostate cancer by dogs sniffing urine: a step forward in early diagnosis. Eur Urol. 2011;59(2):197-201.

4. Roobol MJ, Zhu X, Schroder FH, et al. A calculator for prostate cancer risk 4 years after an initially negative screen: findings from ERSPC Rotterdam. Eur Urol. 2013;63(4):627-33.

5. Djavan B, Mazal P, Zlotta A, et al. Pathological features of prostate cancer detected on initial and repeat prostate biopsy: results of the prospective European Prostate Cancer Detection study. Prostate. 2001;47(2):111-7.

6. Vencalek O, Facevicova K, Furst T, Grepl M. When less is more: a simple predictive model for repeated prostate biopsy outcomes. Cancer Epidemiol. 2013;37(6):864-9.

7. Roehl KA, Antenor JA, Catalona WJ. Serial biopsy results in prostate cancer screening study. J Urol. 2002;167(6):2435-9.

8. Amann A, Spanel P, Smith D. Breath analysis: the approach towards clinical applications. Mini Rev Med Chem. 2007;7(2):115-29.

9. Mazzone PJ. Analysis of volatile organic compounds in the exhaled breath for the diagnosis of lung cancer. J Thorac Oncol. 2008;3(7):774-80.

10. Bokhorst LP, Valdagni R, Rannikko A, et al. A decade of active surveillance in the PRIAS study: an update and evaluation of the criteria used to recommend a switch to active treatment. Eur Urol. 2016;70(6):954-60.

11. Miekisch W, Herbig J, Schubert JK. Data interpretation in breath biomarker research: pitfalls and directions. J Breath Res. 2012;6(3):36007.

12. Kort S, Brusse-Keizer M, Gerritsen JW, Palen J van der. Data analysis of electronic nose technology in lung cancer: generating prediction models by means of Aethena. J Breath Res. 2017;11(2):26006.
13. Kroonenberg P. Applied multiway data analysis. Hoboken: John Wiley \& Sons; 2008.

14. Russo GI, Regis F, Castelli T, et al. A systematic review and metaanalysis of the diagnostic accuracy of prostate health index and 4-Kallikrein panel score in predicting overall and high-grade prostate cancer. Clin Genitourin Cancer. 2017;15(4):429-439.e1.

15. Chan DK, Zakko L, Visrodia KH, et al. Breath testing for Barrett's esophagus using exhaled volatile organic compound profiling with an electronic nose device. Gastroenterology. 2017;152(1):24-6.

16. Bruins M, Rahim Z, Bos A, et al. Diagnosis of active tuberculosis by e-nose analysis of exhaled air. Tuberculosis (Edinb). 2013;93(2):232-8.

17. Hooren MR van, Leunis N, Brandsma DS, et al. Differentiating head and neck carcinoma from lung carcinoma with an electronic nose: a proof of concept study. Eur Arch Otorhinolaryngol. 2016;273(11):3897-903.

18. Nakhleh MK, Amal H, Jeries R, et al. Diagnosis and classification of 17 diseases from 1404 subjects via pattern analysis of exhaled molecules. ACS Nano. 2017;11(1):112-25.

19. Peng G, Hakim M, Broza YY, et al. Detection of lung, breast, colorectal, and prostate cancers from exhaled breath using a single array of nanosensors. Br J Cancer. 2010;103(4):542-51.

20. Goor RM van de, Leunis N, Hooren MR van, et al. Feasibility of electronic nose technology for discriminating between head and neck, bladder, and colon carcinomas. Eur Arch Otorhinolaryngol. 2017;274(2):1053-60.

drs. Claire G. Waltman anios urologie

dr. Joep G.H. van Roermund uroloog 